Progress Report

for

DOE Grant No. DE-FG03-89ER45387

\title{
MECHANICAL PROPERTIES OF MATERIALS WITH NANOMETER SCALE MICROSTRUCTURES
}

\author{
for the period \\ 1 April 1989 to present
}

Submitted to:

Division of Materials Sciences

Office of Basic Energy Sciences

United States Department of Energy

Washington D.C. 20545

Attention: Dr. Joseph B. Darby, Jr.

and Dr. Yok Chen

Submitted by:

Department of Materials Science and Engineering

Stanford University, Stanford California 94305

Principal Investigator: Professor William D. Nix

July 1991

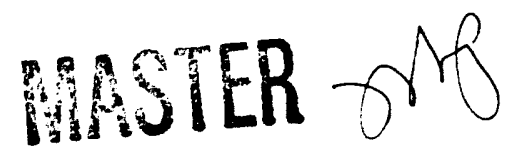

DISTRIBUTIONO OF THIS DOCUMENT IS GALIMITIOD 
Table of Contents

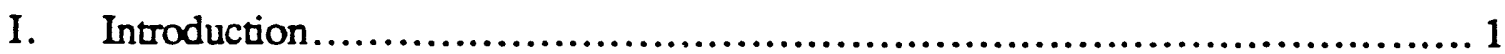

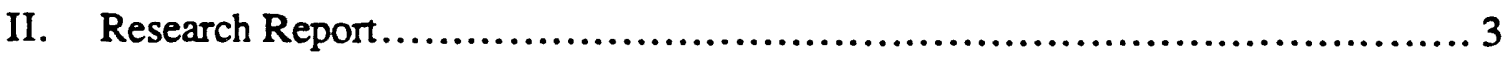

A. The Supermodulus Effect .............................................. 3

B. Strength of Compositionally-Modulated Thin Films......................... 8

C. Mechanical Properties of Nanocrystalline $\mathrm{TiO}_{2}$ and $\mathrm{ZnO}$.......................10

D. The Bulge Test: Theory and Experiment .................................11

1. Finite Element Model.....................................................12

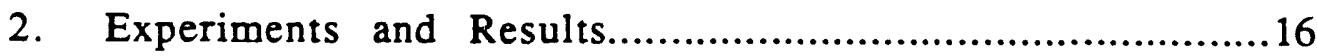

E. Extensions and Improvements in Nanoindenter-based Experiments.........18

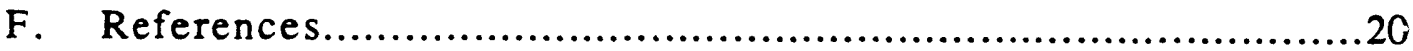

III. Oral Presentations Resulting from DOE Grant No. DE-FG03-89ER45387 .......21

IV. Publications Resulting from DOE Grant No. DE-FG03-89ER45387 ............22

\section{DISCLAIMER}

This report was prepared as an account of work sponsored by an agency of the United States Government. Neither the United States Government nor any agency thereof, nor any of their employees, makes any warranty, expres; or implied, or assumes any legal liability or responsibility for the accuracy, completeness, or usefulness of any information, apparatus, product, or process disclosed, or represents that its use would not infringe privately owned rights. Reference herein to any specific commercial product, process, or service by trade name, trademark, manufacturer, or otherwise does not necessarily constitute or imply its endorsement, recommendation, or favoring by the United States Government or any agency thereof. The views and opinions of authors expressed herein do not necessarily state or reflect those of the United States Government or any agency thereof. 


\section{INTRODUCTION}

For the past two years we have been engaged in a program of research on the mechanical properties of a variety of new materials with nanometer scale microstructures. These materials have been developed recently using vapor phase synthesis techniques and are available in the form of compositionally-modulated (multilayered) thin film materials and ultrafine-grained (nanocrystalline) solids. They have interesting microstructures and mechanical properties that may lead to new applications for these materials. In this report we give a brief summary of some of the results we have obtained to date in the course of this research. Other, more detailed, descriptions of some of this work can be fou. $d$ in the papers that we have published. These are listed at the end of this report along with a listing of the oral presentations we have given.

We report briefly on our studies of the elastic properties of metallic multilayered thin films. Using indentation and microbeam deflection techniques, we have found that $\mathrm{Au} / \mathrm{Ni}$ multilayers do not show supermodulus effects, contrary to some previous reports based on bulge test results. However, we have discovered large and significant substrate interaction stresses in these films which depend systematically on the composition modulation wavelength. We believe that these residual stresses may have led to bulge testing errors which in turn led to erroneous reports of supermodulus effects.

During the course of this work our attention has increasingly been focussed on the remarkable strength properties of metal multilayers. We have found that these materials can exhibit extremely high hardnesses and strengths. In particular, hardnesses of $12 \mathrm{GPa}$ have been observed for the Pt/Cr system. This corresponds to a yield strength of about $4 \mathrm{GPa}$. $\mathrm{Fe} / \mathrm{Zr}$ multilayers also have hardnesses approaching $12 \mathrm{GPa}$. Here we give a brief account of some of this work. More work will be done in this area in the future.

We have investigated the hardnesses and elastic properties of nanocrystalline ceramics using nanoindenter techniques. Although superplasticity was not observed, the nanophase ceramics are found to be deformable at room temperature. Also, the strain rate sensitivity observed for these nanocrystalline materials was found to be four times higher than that for single crystal material. These results show the important effects that high concentrations of grain boundaries can have on the deformation properties of ceramics. 
We report also on the work we have done to develop a bulge testing apparatus and to understand the mechanics of the bulge test itself. By making a finite element analysis of the bulge test, we have identified important corrections that need to be made with the standard spherical membrane equations used to interpret bulge test data. The effect of clamping of the edge of the film is shown to be important. Also, the analysis indicated that reliable experimental data can be obtained only if the films are initially flat. Failure to produce initially flat films will cause anomalously large elastic stiffnesses to be observed. Experimental work with the bulge testing apparatus has shown that reliable results can be achieved if the films are flat and if all of the necessary corrections are made.

Because the Nanoindenter remains one of the central techniques for studying mechanical properties of thin films and multilayers, we are continually working to improve and refine the testing data analysis procedures we use with this instrument. Some of the advances that have been made in Nanoindenter techniques are described briefly. 


\section{RESEARCH REPORT}

In the following report, we briefly describe some of the accomplishments which resulted from work carried out under Department of Energy Grant No. DE-FG03-89ER45387. This includes a possible explanation of the supermodulus effect, the discovery of very high strengths in metal multilayers, a description of the mechanical properties of nanocrystalline ceramics, a new quantitative understanding of the bulge test and several refinements of Nanoindenter techniques.

\section{A. The Supermodulus Effect}

The supermodulus effect has been reported as an anomalous increase of as much as several hundred percent in the elastic moduli of compositionally-modulated films in a narrow range of modulation wavelength $[1,2,3,4,5,6]$. Figure 1 shows a typical result taken from Yang et al. for (111) Au/Ni films tested in a bulge tester. At longer modulation wavelengths, $\lambda$, the measured biaxial modulus is constant. However, as the wavelength decreases near $2 \mathrm{~nm}$, the modulus is seen to increase dramatically. As the elastic properties of a material are generally quite insensitive to structure, this result was quite controversial and has stimulated much research.

We have investigated the mechanical properties of $\mathrm{Au} / \mathrm{Ni}$ multilayers in both indentation and microbeam deflection modes using the Nanoindenter. Samples were provioded by Dr. Alan Jankowski of the Lawrence Livermore National Laboratory and include films deposited onto silicon substrates and onto $\mathrm{SiO}_{2}$ cantilever beam structures. All of the samples were produced by sequentially magnetron sputtering the constituents onto the substrates. In each set of samples a range of modulation wavelengths were provided. The data from the indentation experiments were analyzed using a method developed by Doerner and Nix [7]. Using this method, both the hardness and elastic modulus of the sample can be obtained. Micrometer-scale $\mathrm{SiO}_{2}$ cantilever beam structures were made by lithographic patterning and anisotropic etching techniques. The beams are $1 \mu \mathrm{m}$ thick, $20 \mu \mathrm{m}$ wide, and $50-100 \mu \mathrm{m}$ long. The compositionally-modulated films were then deposited onto the beams and the Nanoindenter was used to deflect the resulting bilayer beams as shown in Figure 2. Using standard mechanics models, the elastic modulus and the yield strength of the film can be obtained from the load-displacement data if the elastic properties of the oxide are known [8]. 


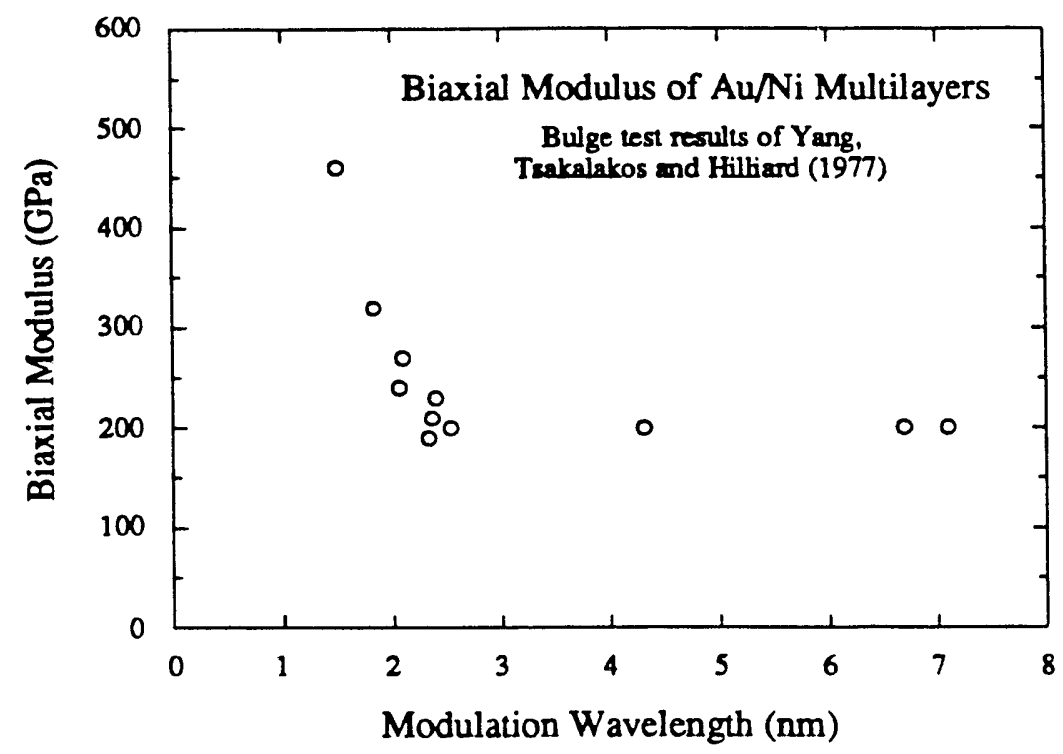

Figure 1. The supermodulus effect in Au/Ni multilayer films (after Yang et al. [1]).

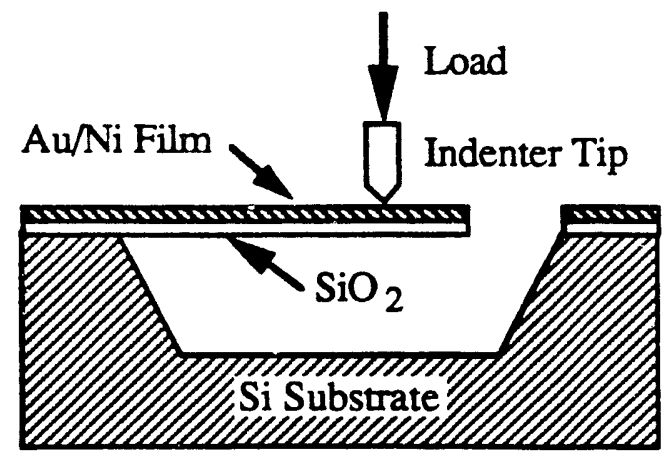

Figure 2. Schematic of the bilayer microbeam deflection experiment used to determine the in-plane stiffness of $\mathrm{Au} / \mathrm{Ni}$ films. 
As shown in Figure 3, no variation in elastic modulus with modulation wavelength was seen in indentation experiments. In addition, no variation in elastic stiffness with modulation wavelength was found by the microbeam deflection technique. The interesting result of this study was, however, that the $\mathrm{SiO}_{2}$ beams, which were initially flat, were curved once the modulated films were deposited. This indicates that there was a substrate interaction stress between the metal film and the substrate. It was found that the curvatures, and therefore the interaction stresses, varied quite strongly with inodulation wavelength. Using a method developed by Weihs [9], the average stress in the film was calculated from the curvature and the geometry of the beams. The results are shown in Figure 4.

The substrate interaction stresses vary strongly with modulation wavelength. It is of interest to determine what effect such stresses might have on bulge test results since this is the technique by which anomalous elastic properties have been measured. If our films were removed from their substrates and were then mounted in a bulge tester in such a way that the lateral dimensions at the boundary of the film were preserved, then the film would bulge out to relieve the compressive stresses. If this initial bulge height were not accounted for in the subsequent analysis of bulge test data, then the results would be seriously in error.

To simulate the effects of the measured stresses on bulge tests, the measured stress of the $3.98 \mathrm{~nm}$ wavelength sample was first subtracted from the measured stress of tile other sampl'zs. This was done to remove what are presumably deposition stresses and assumes that the wavelength-dependent stresses are minimal at this wavelength. The expected biaxial modulus was calculated from published values of the elastic constants of $\mathrm{Au}$ and $\mathrm{Ni}$. The initial bulge heights were then calculated at each wavelength from the reduced stresses and the expected modulus. Pressure-displacement curves were then generated based on the absolute real bulge height and the input biaxial modulus. These data were then converted to stress-strain data without accounting for the initial bulge height. The pressure-displacement and stress-strain curves were calculated using the spherical membrarie equations described below. 


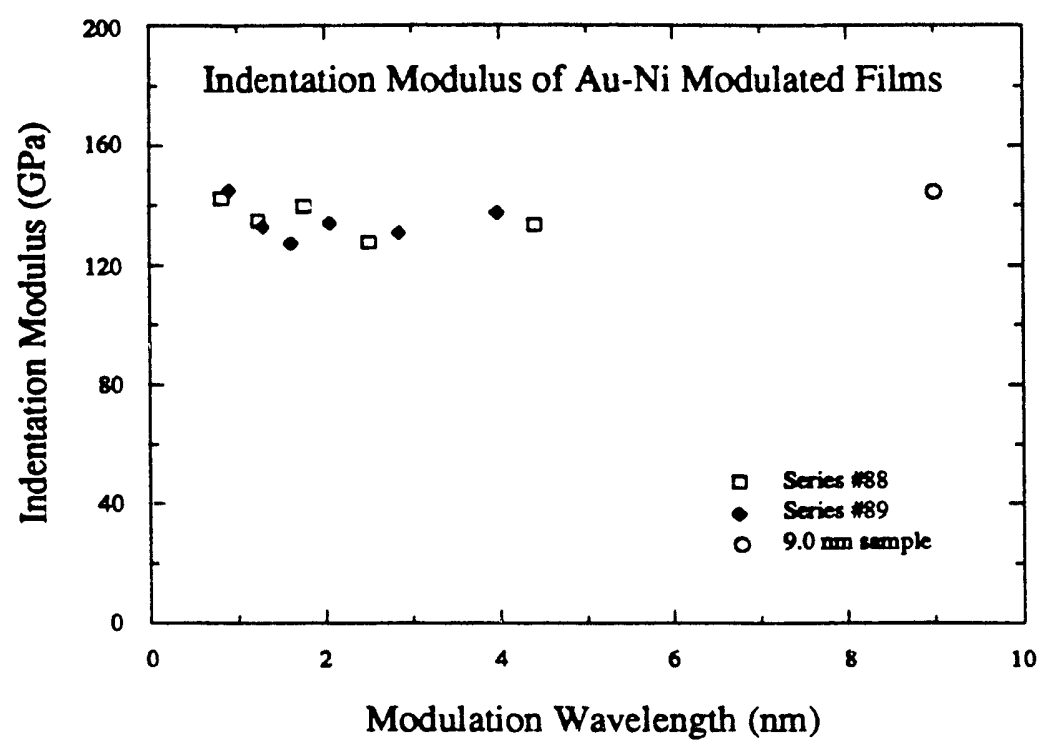

Figure 3. The elastic modulus of $\mathrm{Au} / \mathrm{Ni}$ multilayered thin films as measured using an indentation rechnique.

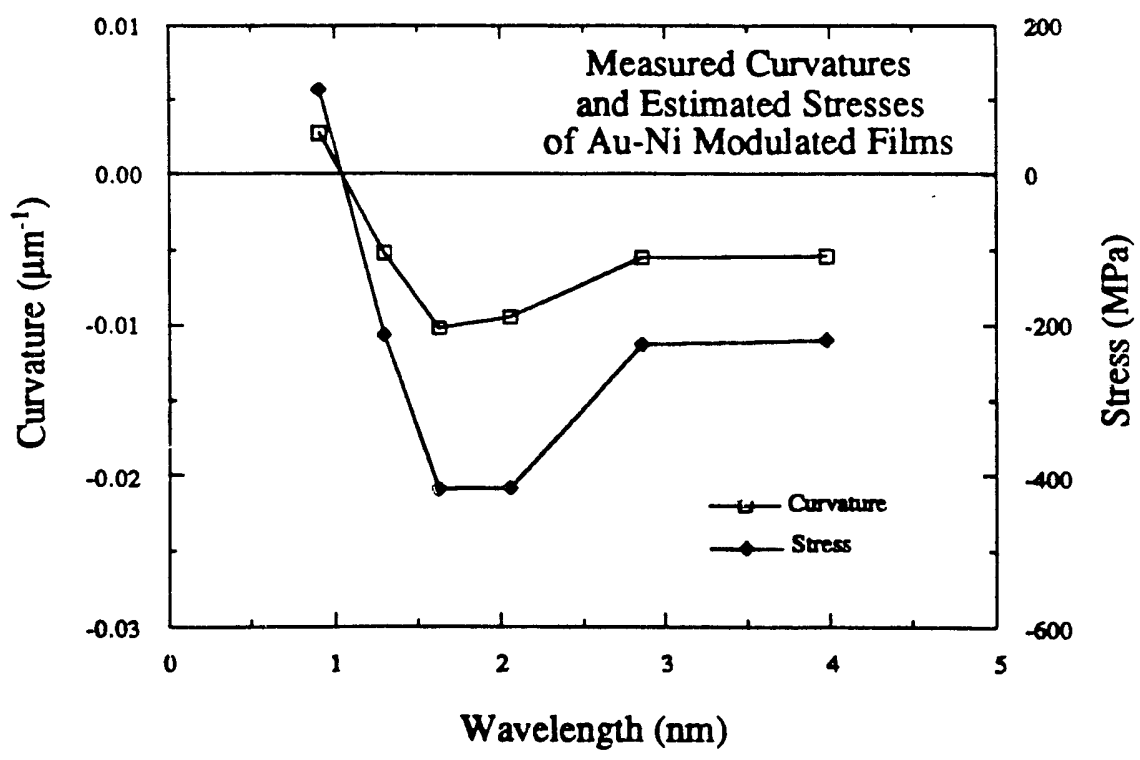

Figure 4. Measured curvatures and the corresponding substrate interaction stresses. 
A typical stress-strain plot is shown in Figure 5. The data are non-linear even though the strains are well within the elastic regime, in accordance with the results reported by all authors reporting the supermodulus effect. Taking the biaxial modulus to be the initial slope of this curve, as did the supermodulus authors, the value is found to be much higher than the input value. This procedure was repeated for all of the samples in this study. The simulated bulge test results are as shown in Figure 6. Although the magnitudes of the simulation moduli are much greater than those reported by the supermodulus authors, the location and sign of the peak are in agreement. It is unlikely that the films which were tested in the supermodulus experiments were handled in such a way that the substrate interaction stresses were preserved during sample mounting in the bulge tester. Our simulations show that, even if only small portions of those stresses were preserved, large errors in elastic modulus could be produced. We therefore conclude that the large elastic anomalies reported from bulge test experiments could be artifacts that result from wavelength-dependent stresses in the tested films. We note that, with the exception of the microtensile tests [5, 6], all of the other experimental tec!.niques by which large modulus enhancements were found are subject to errors which could result from wavelengthdependent substrate interaction stresses or stress gradients within the films.

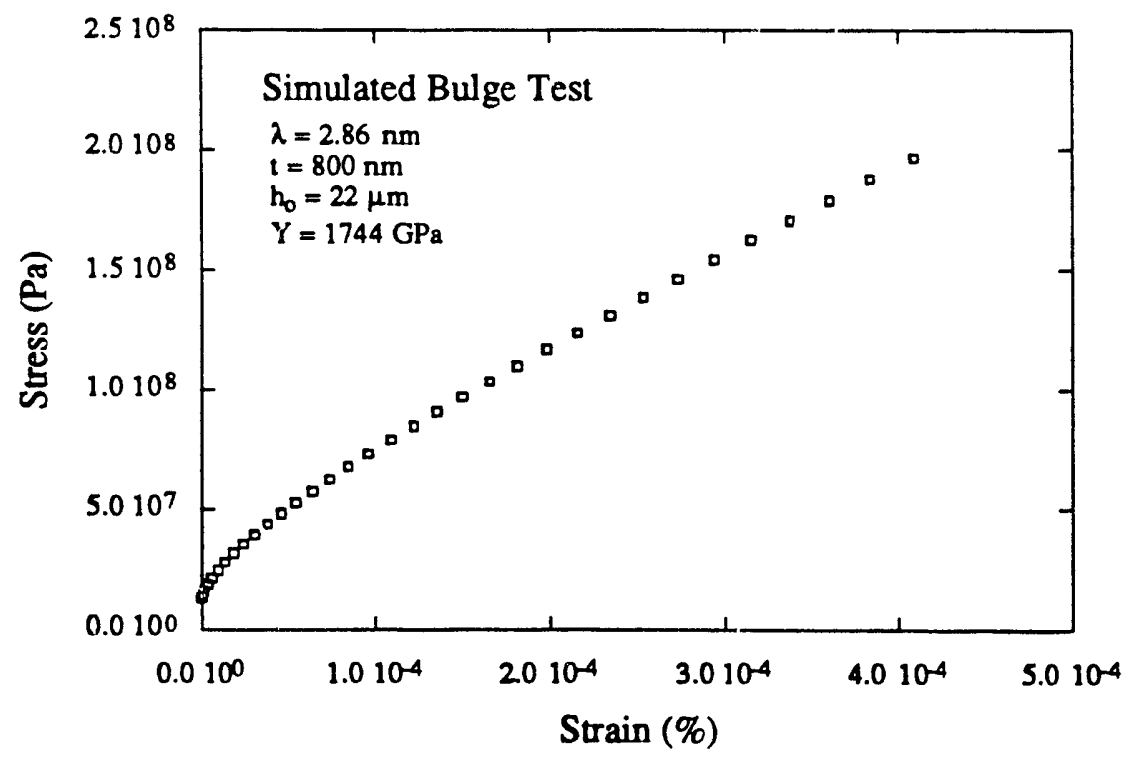

Figure 5. Simulated stress-strain curve for bulge test of an Au/Ni multilayer film. 


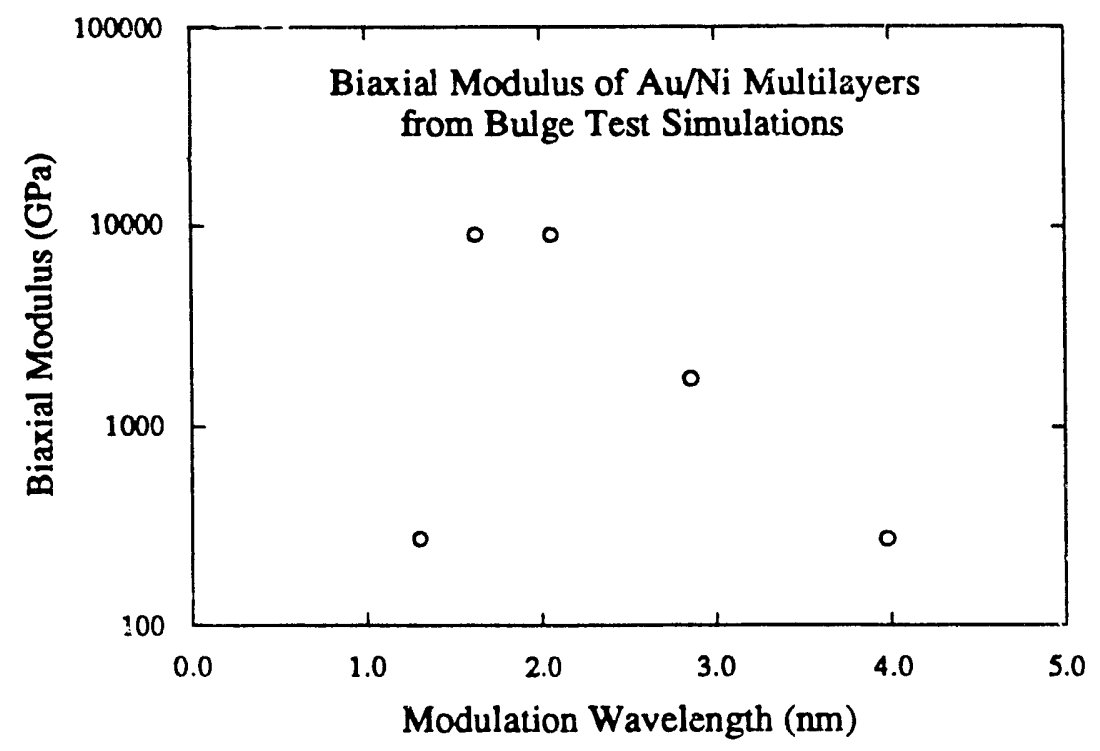

Figure 6. Results of bulge test simulations.

\section{B . Strength of Compositionally-Modulated Thin Films}

During the course of this program, a variety of multilayered metal thin film systems were tested. Initially, our interest in such systems was motivated by our research on the supermodulus effect. However, as more became known about the mechanical properties of this class of materials, our attention tuned more towards the unusually high strengths of these materials. Our col'aborator, Dr. Troy W. Barbee Jr. of the Lawrence Livermore National Laboratory, has provided us with several different sets of multilayer films including $\mathrm{Cu} / \mathrm{Zr}, \mathrm{Pt} / \mathrm{Cr}, \mathrm{Cu} / 304$ stainless steel and $\mathrm{Cu} / \mathrm{Monel}$, all of which we have tested by indentation using the Nanoindenter. In ali of these systems we have found elastic properties which are insensitive to modulation wavelength and hardnesses which can vary quite strongly. In some cases, the maximum hardnesses can be quite high. For example, hardnesses of $12 \mathrm{GPa}$ were found in the Pt/Cr system, this is twice the hardness of tungsten, which is the hardest elemental metal. We present here, as an example, results of a study of the mechanical properties of $\mathrm{Fe} / \mathrm{Zr}$ multilayers which were produced here at Stanford in the Center for Materials Research. 
$\mathrm{Fe} / \mathrm{Zr}$ multilayered films were fabricated by sputter deposition of the constituents onto glass substrates. The composition modulation wavelength of the films varies between 0.83 and $92 \mathrm{~nm}$ and the average composition varies between 40 and 50 at\% $\mathrm{Zr}$. The structures of these films were studied using $x$-ray diffraction and high resolution electron microscopy. The $\mathrm{Fe}$ and $\mathrm{Zr}$ layers were found to have strong (110) and (001) fiber textures respectively. For modulation wavelengths greater than $4.3 \mathrm{~nm}$ the multilayers are crystalline with amorphous interfaces; for smaller wavelengths the samples are entirely amorphous. Below $0.83 \mathrm{~nm}$ no layered structure is observed. The hardness and structural parameters are shown as a function of modulation wavelength in Figure 7. For wavelengths greater than $4.3 \mathrm{~nm}$, the hardness increases only slightly with decreasing wavelength. For smaller wavelengths however, the hardness increases quite dramatically to a value approximately $60 \%$ higher than that for greater wavelengths. The elastic modulus does not show any systematic variation with wavelength; the average value is $127 \mathrm{GPa}$.

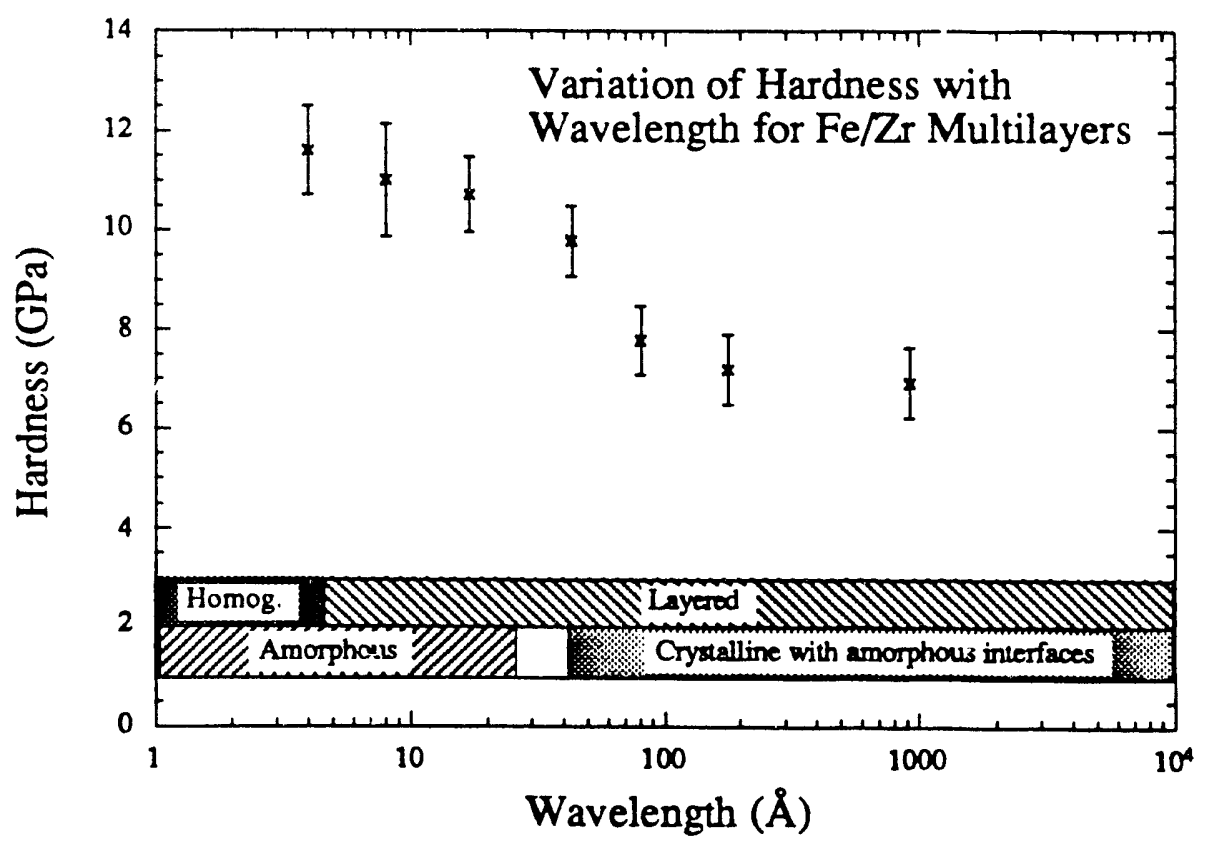

Figure 7. Mechanical properties as measured by indentation and structure as determined by TEM and $x$-ray methods as a function of composition modulation wavelength. 
Tnese preliminary results indicate not only that the strengths of these materials can be finely controlled by adjusting their microstructures, but that extremely high strengths are attainable. The possibility of creating and understanding super-strong films and coatings is one of the principal motivations behind this work.

\section{Mechanical Properties of Nanocrystalline $\mathrm{TiO}_{2}$ and $\mathrm{ZnO}$}

Through our collaborations with Dr. R.W. Siegel of the Materials Science Division of the Argonne National Laboratory and Professor M.J. Mayo of the Department of Materials Science and Engineering at the Pennsylvania State University we have studied the mechanical properties of nanocrystalline $\mathrm{TiO}_{2}$ and $\mathrm{ZnO}$ using Nanoindenter techniques [10, 11]. The materials were made at the Argonne National Laboratory by the gas phase condensation technique and were received in both the as-compacted state and in various sintered states. The as-compacted nanophase $\mathrm{TiO}_{2}$ had been shown in previous work to have a grain size of about $12.2 \mathrm{~nm}$. The grain size of the $\mathrm{ZnO}$ in the as-compacted state was determined to be $7.4 \mathrm{~nm}$. Sinteriny of these materials at temperatures up to $900^{\circ} \mathrm{C}$ causes both densification and grain growth to occur. The densities typically increase from about $75 \%$ in the as-compacted state to about $90 \%$ after sintering at the highest temperature. The grain size of $\mathrm{TiO}_{2}$ increases to about $240 \mathrm{~nm}$ after sintering at $900^{\circ} \mathrm{C}$. For $\mathrm{ZnO}$ the grain size increases to $140 \mathrm{~nm}$ after sintering at $700^{\circ} \mathrm{C}$. Room temperature indentation experiments were conducted in an effort to determine the "deformability" of thesa materials as well as to measure the elastic modulus, hardness and strain rate sensitivity as a function of sintering temperature.

Because these nanocrystalline ceramics have a high concentration of grain boundaries in the as-compacted state, they are observed to exhibit plastic deformation when tested in the indentation mode at room temperature. We observed that nanocrystalline $\mathrm{TiO}_{2}$ could be indented without forming cracks at the corners of the indent, whereas single crystal rutile exhibited well defined cracks, typical of a brittle ceramic tested at room temperature. The ability of the nanocrystalline $\mathrm{TiO}_{2}$ to deform without cracking is indicative of the plasticity that is possible in these materials.

We have measured the average elastic moduli (indentation moduli) as well as the hardnesses of these ceramics as a function of sintering temperature. In general, these properties were found to vary significantly from place to place within a given sample, indicating a high degree of structural inhomogeneity. In spite of this, a systematic evolution of properties was observed as a function of sintering temperature. Indentation 
modulus and hardness both increase almost linearly with increasing sintering temperature.

We believe this variation is caused mainly by the densification that occurs during sintering.

Because the as-compacted materials have such small grain sizes, it is tempting to think that superplasticity might be observed, even at temperatures as low as room temperarure. Thus we measured the strain rate sensitivity using indentation techniques [12] in an effort to determine if the high strain rate sensitivities typical of superplasticity might be observed. While the measured strain rate sensitivity for these materials uloes not suggest superplasticity, we did observe very significant variations in strain rate sensitivity with sintering temperature. For both $\mathrm{TiO}_{2}$ and $\mathrm{ZnO}$ we found that the strain rate sensitivity for the as-compacted nanoctystalline ceramic is about 0.04 , about twice that of the grain coarsened ceramics. As another point of comparison, the strain rate sensitivity for single crystal rutile $\left(\mathrm{TiO}_{2}\right.$ ) was found to be 0.01 . These results indicate that, although superplastic deformation has not been found in these nanocrystalline materials, "high" strain rate sensitivities have been observed. We believe these results indicate that the presence of high angle grain boundaries in these materials changes the characteristics of plastic deformation and makes these ceramics more deformable.

By using our specialized nanometer-scale mechanical testing techniques, we have made significant progress in quantifying the room temperature deformation properties of nanoctystalline ceramics. Further work would require high temperature mechanical testing techniques to be developed. While this can be done now using bulk samples, it is not yei possible to do it on the nanometer scale. When and if a high temperature nanoindenter becomes available, it will be possible to further the study of the mechanical properties of these interesting materials.

\section{The Bulge Test: Theory and Experiment}

We have constructed a bulge tester as a part of our work in studying the mechanical properties of thin films. With this device, pressure is applied to one side of a free-standing thin film and the height of the resulting bulge is measured interferometrically. Using a model for deformation behavior in a bulge test, one can determine stress and strain, and related mechanical properties such as the biaxial modulus, for a material thus tested. In the process of conducting experiments with the apparatus, however, we discovered several sources of error in this test. We have used finite element modeling to characterize the sources of such errors and to further our understanding of the bulge test. This work was done in conjunction with experiments designed to verify the modei predictions. 


\section{Finite Element Model}

Several models have been used in the past to convert the pressure-displacement data obtained from a bulge test into stress and strain. The oldest and most commonly used is the spherical membrane approximation [13]. This model makes the assumption that a film in a bulge test behaves like a section of a thin-walled, spherical pressure vessel. The derivation of equations for stress and strain based on pressure, displacement, and sample geometry is straightforward and can easily be modified to accommodate various initial conditions. The equations for stress and strain for an initially flat, unstressed film are as follows:

$$
\sigma=\frac{\mathrm{Pa}^{2}}{4 \mathrm{ht}}
$$

and

$$
\varepsilon=\frac{2 h^{2}}{3 a^{2}},
$$

where $P$ is the pressure, $a$ is the film radius, $h$ is the bulge height, and $t$ is the film thickness. While the model is simple, it is not completely accurate. In a thin-walled pressure vessel the stresses and strains are everywhere the same, whereas in a bulge test the circumferential strain at the edge must be zero due to the clamping constraint. This discrepancy, along with large variations in reported test results from the same material [1, 14], prompted us to examine the models used to analyze deformation behavior in bulge tests; we accomplished this through the use of the finite element method.

The problem was reduced to two dimensions by using axisymmetric shell elements. The boundary conditions are that the film is fixed at the edge and not allowed to rotate, and the center must remain along the axis of symmetry and remain smooth. The model was modified to account for slack, which commonly arises because of compressive stress in a film still attached at the edge to its substrate, and tension in the film. Also modeled were the effects of uncertainty in film displacement and variation in elasi $=$ constants.

The value of the biaxial modulus calculated from the spherical membrane equations for an initialiy flat, unstressed film is surprisingly close to the finite element result, differing mostly in its dependence on Poisson's ratio. The difference is caused by the clamping constraint. At the edge of the film the circumerentiai strain is zero. The circumferentiai 
stress, found from Hooke's law, is $v \sigma_{\mathrm{r}}$, where $v$ is the Poisson's ratio and $\sigma_{\mathrm{r}}$ is the radial stress. Near the edge of the film, therefore, the stress is more nearly uniaxial, with the consequence that the film is more compliant than if the stress were everywhere equi-biaxial. The variation of calculated biaxial modulus with Poisson's ratio is systematic, however; and can now be accounted for in analyzing bulge test data.

Analysis of the model for slack films, combined with experimental observations, reveal that compressive stresses at the edge of the film are not relieved even at large pressures and displacements. Since these films are too thin to sustain compressive stresses without buckling, they will be wrinkled throughout most of the test, thereby destroying the axisymmetry of the problem. All models developed to date for slack films are based on an axisymmetric shape for the bulge. Therefore, at present the available theory does not accurately model the deformation behavior of wrinkled films and reports of bulge test results from such samples should be treated with caution.

Residual tensile stresses are also common in thin films on substrates. The effect of residual tension on bulge test data is to make the film appear much stiffer than if it were stress-free, rather like pushing on a taut drumhead. Even an initial stress of only $10 \mathrm{MPa}$ makes the film appear to be several times stiffer than if it were unstressed. The error can be virtually eliminated by using an equation for strain which has been modified to account for the residual stress. We compared the deformation behavior predicted by the stress and modified strain equations to the finite element model for several different initial stresses. Figure 8 shows plots of initial stresses and biaxial moduli calculated from the finite element output using the spherical shell equations. The results, which are normalized by the respective input values, are plotted against the initial stresses for various Poisson's ratios. The figure shows that there is a slight dependence of the calculated biaxial modulus on initial stress and a greater dependence on Poisson's ratio. The calculated value of the initial stress is virtually identical to that input into the model, which indicates that the bulge test can be a useful tool in measuring residual stresses in thin films. As discussed earlier, this variation in biaxial modulus arises because the spherical membrane equations do not account for the effects of the clamping constraint at the edge of the film. Based on this finite element work, we have developed algorithms for determining the correct biaxial modulus from bulge test data. 


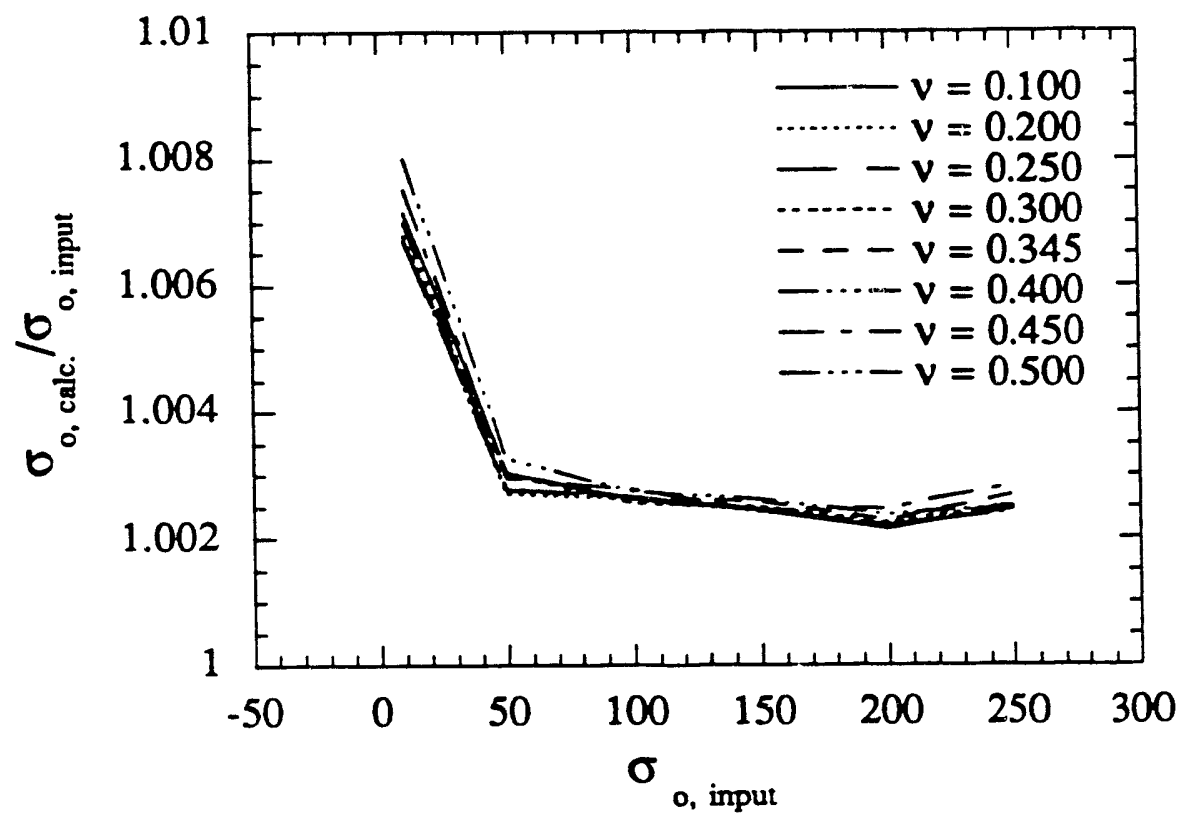

(a)

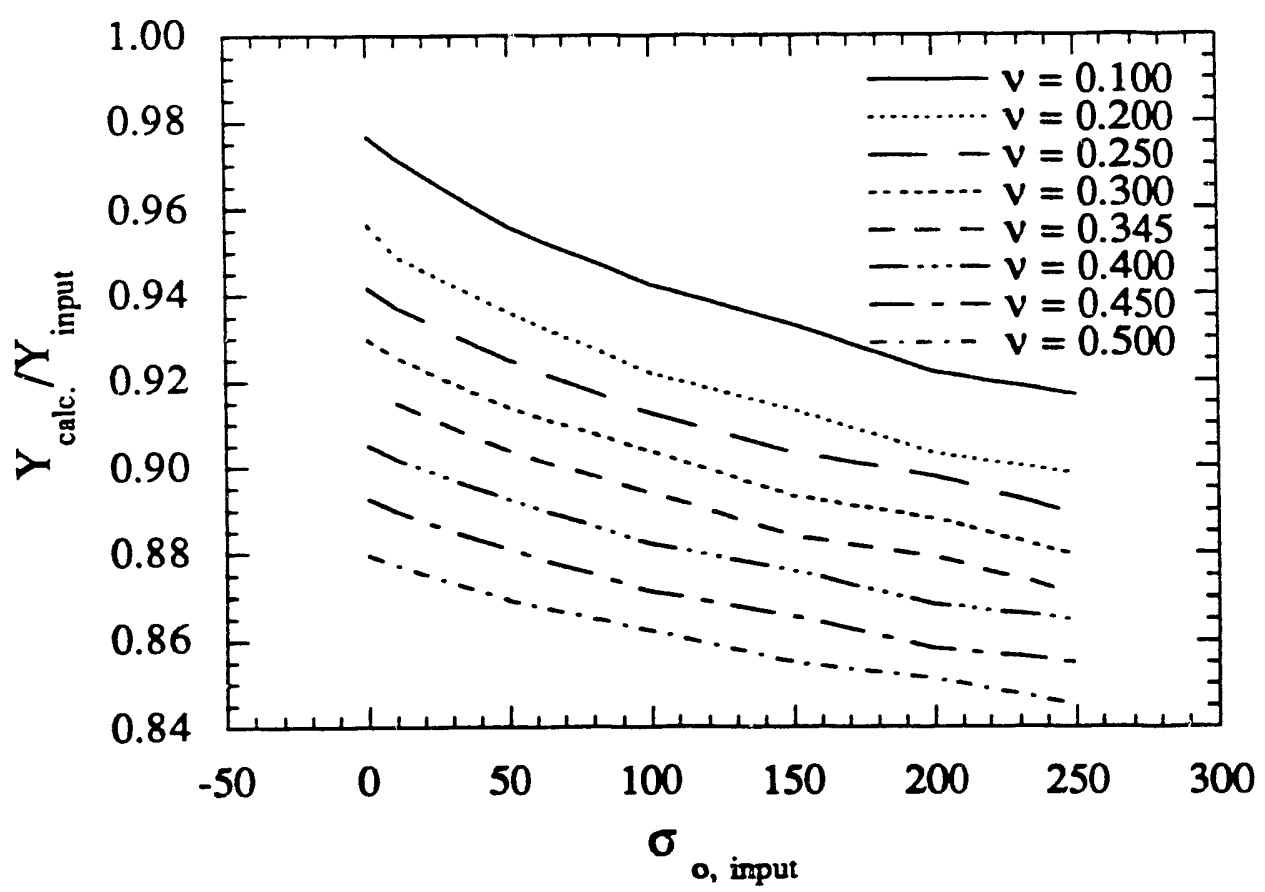

(b)

Figure 8. Ratio of calculated to input a) biaxial modulus and b) initial stress as a function of initial stress and Poisson's ratio. 
In the preceding discussions it was assumed that the bulge height is known absolutely. In practice, however, that is often not the case. The most commonly employed methods of measuring film dispiacement, most notably interferometry, can detect very small changes in position, but are less accurate in determining position relative to some reference. This problem is overcome by the microscope focusing technique[15], but at the cost of a factor of two or more in the resolution. The magnitude of the effect of an uncertainty in the film height is illustrated in Fig. 9, which shows a plot of pressure-displacement curves begun at several different heights. Because the initial, flat part of the curve has been eliminated the material appears much stiffer. Using the properties of aluminum and calculating the biaxial modulus from the latter part of the curve, which appears more linear, we find that an initial height of only $25 \mu \mathrm{m}$ results in a $30 \%$ increase in the calculated biaxial modulus. Even though the initial section has been removed, the pressure-displacement curve still has a characteristic shape. Using this information we have developed a fitting procedure which effectively eliminates the uncertainty error. The procedure has been verified by the finite element model.

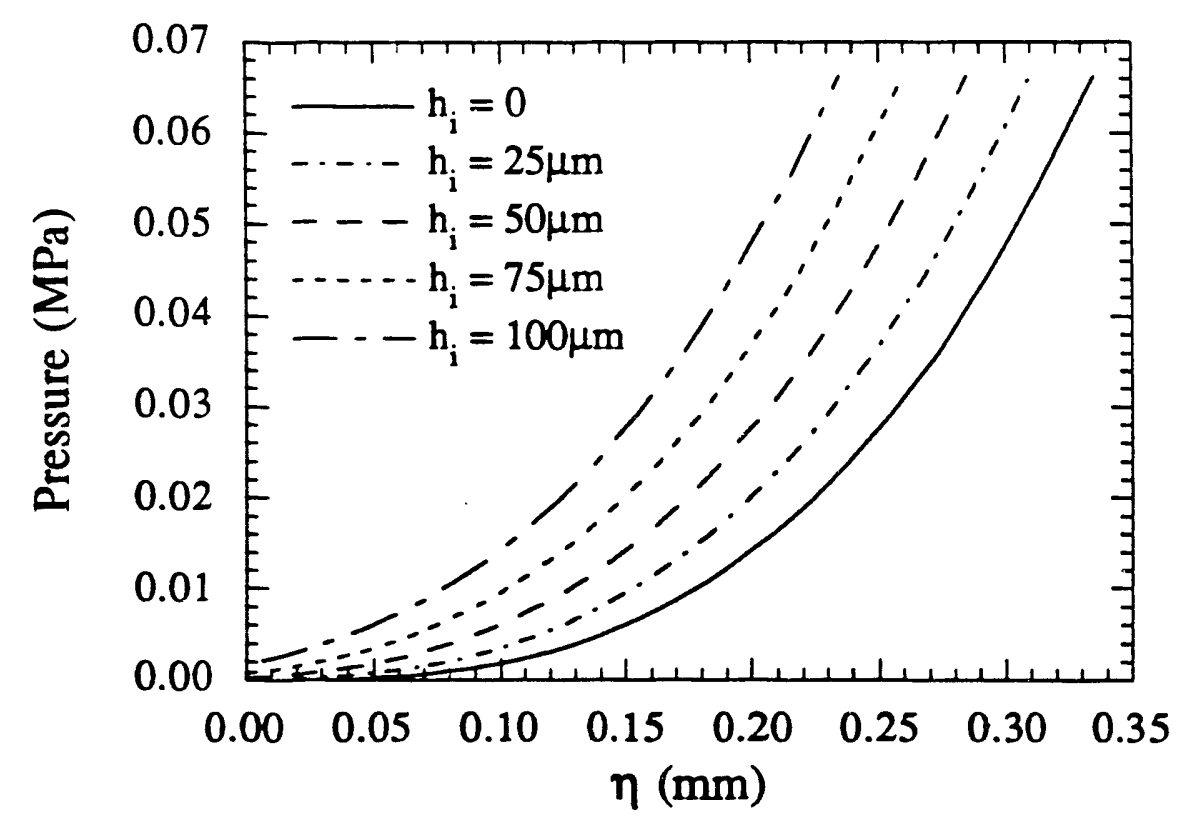

Figure 9. Pressure-displacement curves from the finite element "data", plotted for different initial heights. 
Much of the variation in the measured properties of identical materials can be attributed to an incomplete understanding of the bulge test itself. The finite element results have shown that, with a few simple modifications, the spherical cap equations can be used to accurately determine film properties from the bulge test. They have also pointed to potentially large sources of error in interpreting bulge test data. Perhaps the most important factors to take into consideration are the effects of initial conditions. It is nearly impossible to obtain accurate results from a bulge test without determining the residual stress in the film and the absolute height of the bulge. In addition, sample preparation is very important. The equations for slack films do not represent actual behavior, and there is no model currently available that can predict the behavior of films with a non-axisymmetric initial stress state. Therefore, we find that flat films are required if one is to obtain accurate results from the bulge test.

\section{Experiments and Results}

In order to characterize the bulge tester and gain better understanding of which factors influence the experimental results, we have tested silver films and compared the measured biaxial moduli with the literature value. The films were $2 \mu \mathrm{m}$ thick and were produced by sputtering onto glass slides. X-ray diffraction experiments showed that the films did not have a strong texture. One would therefore expect the films to have an isotropic biaxial modulus of $131 \mathrm{GPa}$.

A typical pressure-displacement curve is shown in Figure 10. Using the spherical membrane equations, the pressure-displacement curve can be converted into a stress-strain curve. A typical stress-strain curve is shown in Figure 11. The average biaxial modulus for a series of eleven tests was $108 \pm 19 \mathrm{GPa}$. This is lower than the expected value and we attribute this difference to two factors. First, the data was analyzed using the spherical membrane equations. From the finite element analysis of the bulge test, however, we know that these formulas underestimate the biaxial modulus. Second, the compliance of the glue used to mount the samples influences the measurement and tends to decrease the measured modulus. It also accounts for most of the scatter in the data. The compliance of the glue cannot be easily quantified and improved sample mounting procedures are therefore required. Efforts are under way to use the extensive micromachining facilities available at Stanford in order to make framed free-standing films. In addition to eliminating the glue, this procedure should give us extremely good control over sample geometry. 


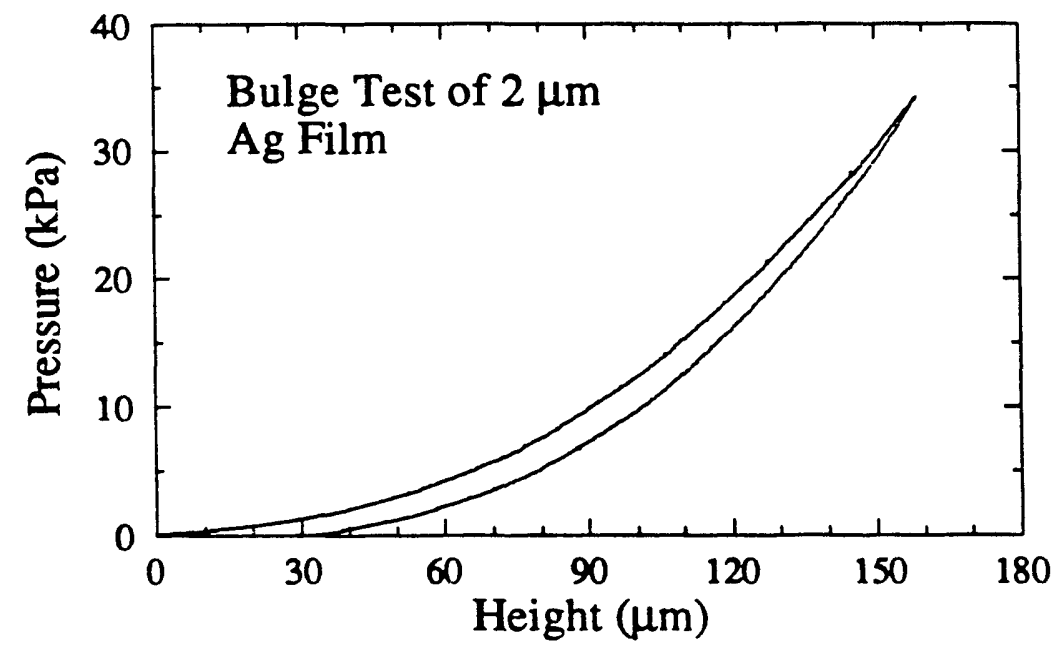

Figure 10. Typical pressure-displacement data from a bulge test of a $2 \mu \mathrm{m}$-thick sputtered Ag film.

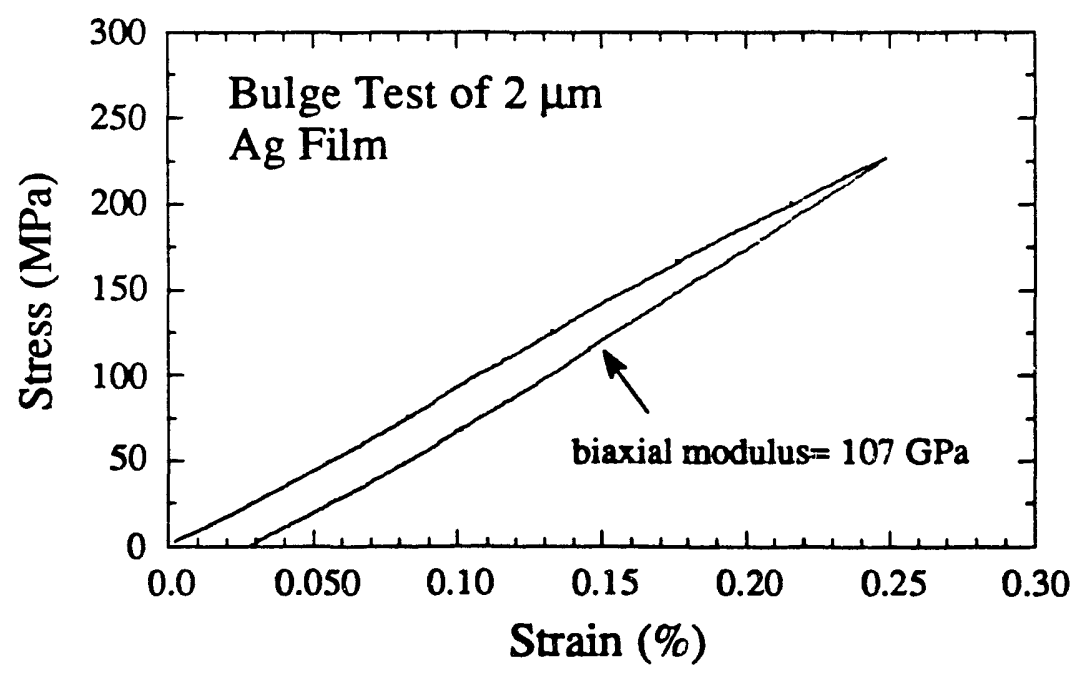

Figure 11. The pressure-displacement data of Figure 10 converted to stress and strain using the methods described above. 
We have also tested a series of polyimide isoindoloquinazolinedione (PIQ) films. One of the benefits of testing polyimide films is that flat samples can be readily prepared. As mentioned in the previous section, this is an important condition for obtaining accurate data from a bulge test. The polyimide films can also be used as substrates for metal films. Once the properties of the polyimide are known, this novel sample preparation technique allows us to determine the mechanical properties of extremely thin metal films. Samples were prepared by spin coating polyimide on Si wafers to a thickness of $2.15 \mu \mathrm{m}$ and were removed in such a way as to preserve the residual stresses in the films. A $20 \mathrm{~nm}$ Au layer was sputtered onto the samples in order to enhance the reflectivity of the films. The polyimide-Au composite shows linear elastic behavior over the entire strain range. Assuming bulk properties for the Au, the biaxial modulus of the polyimide is found to be $6.2 \mathrm{GPa}$, in agreement with values reported in the literature $[16,17]$. The average residual stress in the films is $15 \pm 3 \mathrm{MPa}$. Agair, this value is consistent with residual stresses reported in the literature for similarly prepared films $[15,16,18]$.

There are several sources of error in the bulge test that arise out of an incomplete understanding of the test itself. As a result of cur study of this experiment using the finite element model, as we'l as experience gained in conducting experiments, we can now virtually eliminate these effects.

\section{E. Extensions and Improvements in Nanoindenter-based Experiments}

As a result of our efforts to determine the mechanical properties of small volumes of material we have continued to extend and refine experimental techniques using the Nanoindenter. Some of our recent work in this area is described in this section.

The Nanoindenter is an extremely sensitive mechanical device which can detect displacements of less than $1 \mathrm{~nm}$. As a result, it is subject to extraneous displacements which occur as a result of thermal expansions which arise as the temperature of the apparatus changes during an experiment. We have developed methods for measuring and removing these thermal drift effects, which have enabled us to obtain results from both hard materials (in which the plastic displacements are small and the drift displacements are relatively large) and soft materials (in which large plastic displacements and rate sensitivity require long hold times, allowing drift errors to accumulate) which are otherwise unattainable. For example, we can obtain strain rate sensitivities in hard, brittle materials. 
The method developed by Doemer and Nix [7] for interpreting the data obtained from depth-sensing indentation experiments depends on a flat punch model of the contact between the indenter and the sample material. Implicit in this model is the assumption that the contact area remains constant during unloading. This assumption is good for relatively soft materials, but is less accurate for hard materials. We have developed a new method which, although it incorporates a more realistic assumption of the shape of the tip, is less sensitive to that shape than current methods. In this technique, the more accurate tip shape is used in an elastic contact model in a way similar to that of Doerner and Nix. However, the elastic displacements at the indentation boundary are integrated to obtain the total elas ic displacement of the indenter. The remaining displacements are then plastic if thermal drift has been removed.

The analysis of data from beam deflection experiments assumes the beams to be simply supported (that is, rigidly fixed at the constraining end). However, in reality, there are additional compliances at the fixed end of the beam due both to undercutting, which results from the manufacturing process, and to the compliance of the material to which the beam is attached. The simple support is a good assumption for teflections of very long beams. However, for short beams, the additional compliances introduce errors. Methods by which these additional compliances can be accounted for have been developed and used to obtain elastic properties of $\mathrm{SiO}_{2}$. 


\section{F. References}

1. W. M. C. Yang, T. Tsakalakos and J. E. Hilliard, J. Appl. Phys. 48, 876 (1977).

2. L. R. Testardi, R. H. Willens, J. T. Krause, D. B. McWhan and S. Nakahara, J. Appl. Phys. 52, 510 (1981).

3. G. E. Henein and J. E. Hilliard, J. Appl. Phys. 54, 728 (1983).

4. T. Tsakalakos and J. E. Hilliard, J. Appl. Phys. 54, 734 (1983).

5. D. Baral, J. B. Ketterson and J. E. Hilliard, J. Appl. Phys. 57, 1076 (1985).

6. A. Jankowski and T. Tsakalakc's, J. Appl. Phys. 57, 1076 (1985).

7. M. F. Doerner and W. D. Nix, J. Mater. Res. 1, 601 (1986).

8. T. P. Weihs, S. Hong, J. C. Bravman and W. D. Nix, J. Mater. Res. 3, 931 (1988).

9. T. P. Weihs, PhD Dissertation (1990).

10. M. J. Mayo, R. W. Siegel, A. Narayanasamy and W. D. Nix, J. Mater. Res. 5, 1073 (1990).

11. M. J. Mayo, R. W. Siegel, Y. X. Liao and W. D. Nix, submitted to J. Mater. Res. (1991).

12. M. J. Mayo and W. D. Nix, Acta metall. 36, 2183 (1988).

13. J. W. Beams, Structure and Properties of Thin Films Proc. (edited by C. A. Neugebauer, J. B. Newkirk and D. A. Vermilyea) 18: (1959).

14. H. Itozaki, $\mathrm{PhD}$ Dissertation (1982).

15. M. Mehregany, M. G. Allen and S. D. Senturia, IEEE Solid State Sensors Workshop (1986).

16. S. Senturia, Transducers ' 8711 (1987).

17. V. E. Smirnova and M. I. Bessonov, Polyimides: Materials, Chemistry and Characterization: Mechanical and Optical Anisotropy of Oriented Polyimide Films (edited by C. Feger, M. M. Khojasteh and J. E. McGrath). Elsevier Science Publishers B. V., Amsterdam (1989).

18. M. Mehregany, R. T. Howe and S. D. Senturia, J. Appl. Phys. 62, 3579 (1987). 


\section{ORAL PRESENTATIONS RESULTING TROM DOE GRANT NO. DE- FG03-89ER45387}

1. A. Jankowski, Lawrence Livermore National Laboratory, Livermore, CA; S.P. Baker, W.D. Nix, Department of Materials Science and Engineering, Stanford University, Stanford, CA; K.A. Green and S.R. Nutt, Brown University, Providence R.I., "Gold-Nickel Multilayer Films: Structure-Property Correlations", Symposium C, Thin Films: Stresses and Mechanical Properties, 1988 Fall Meeting of MRS, Boston MA, November 1988.

2. S.P. Baker, W.D. Nix, S. Hong and A.F. Jankowski, "Mechanical Properties of Compositionally Modulated Au-Ni Thin Films Using Indentation and Microbeam Deflection Techniques", Symposium on Thin Films: Stresses and Mechanical Properties, Spring Mecting of the Materials Research Society, San Francisco, April 16, 1990.

3. S.P. Baker and W.D. Nix, "Mechanical Properties of Thin Films on Sutstrates", Symposium on Optical Thin Films New Developments, SPIE The International Society for Optical Engineering, San Diego, CA, July 9-11, 1990.

4. W.D.Nix, "Mechanical Properties of Thin Films", Special Foreigner's Lecture, Japan Institute of Metals, Tohoku University, Japan, September 24, 1990.

5. L.J. Vlassak, T. Nakayama and W.D. Nix, "Structure and Mechanical Properties of Fe/Zr Multilayers" Symposium on Thin Films: Stresses and Mechanical Properties III, Fall Meeting of the Materials Research Society, Boston, MA, December 2-6, 1991.

6. M.K. Small, J. Vlassak and W.D. Nix, "Re-Examining the Bulge Test: Methods for Improving Accuracy and Reliability" Symposium on Thin Films: Stresses and Mechanical Properties III, Fall Meeting of the Materials Research Society, Bostcn, MA, December 2-6, 1991).

7. S.P. Baker and W.D. Nix, "Time-Dependent Deformation in RoomTemperature Indentation Experiments using a Nanoindenter" Symposium on Thin Films: Stresses and Mechanical Properties III, Fall Meeting of the Materials Research Society, Boston, MA, December 2-6, 1991). 


\section{PUBlicAtions RESUlting FROM DOE GRANT NO. DE-FG03- 89ER45387}

1. S.R. Nutt, K.A. Green, S.P. Baker, W.D. Nix and A. Jankowski, "GoldNickel Multilayer Films: Structure-Property Correlations", Materials Research Symposium Proceedings. 130, 129 (1989)

2. M.J. Mayo, R.W. Siegel, A. Narayanasamy and W.D. Nix, "Mechanical Properties of Nanophase $\mathrm{TiO}_{2}$ as Determined by Nanoindentation", Journal of Materials Research, 5, 1073 (1990).

3. S.P. Baker, A.F. Jankowski, S. Hong and W.D. Nix, "Mechanical Properties of Compositionally Modulated Au-Ni Thin Films Using Indentation and Microbeam Deflection Techniques", Materials Research Symposium Broceedings. 188, 289-294 (1990).

4. S.P. Baker and W.D. Nix, "Mechanical Properties of Thin Films on Substrates", in Optical Thin Films III: New Developments, Proc. SPIE, 1323, 263-276 (1990).

5. M.J. Mayo, R.W. Siegel, Y.X. Liao and W.D. Nix, "Nanoindentation of Nanocrystalline ZnO", (submitted to Joumal of Materials Researcli)

6. J.J. Vlassak, T. Nakayama and W.D. Nix, "Structure and Mechanical Properties of $\mathrm{Fe} / \mathrm{Zr}$ Multilayers" (to be published in the Proceedings of the Symposium on Thin Films: Stresses and Mechanical Properties III, Eds: W.D. Nix, J.C. Bravman, L.B. Freund and E. Arzt, Fall Meeting of the Materials Research Society, Boston, MA, December 2-6, 1991).

7. M.K. Small, J. Vlassak and W.D. Nix, "Re-Examining the Bulge Test: Methods for Improving Accuracy and Reliability" (to be published in the Proceedings of the Symposium on Thin Films: Stresses and Mechanical Properties III, Eds: W.D. Nix, J.C. Bravman, L.B. Freund and E. Arzt, Fall Meeting of the Materials Research Society, Boston, MA, December 2-6, 1991).

8. S.P. Baker and W.D. Nix, "Time-Dependent Deformation in RoomTemperature Indentation Experiments using a Nanoindenter" (to be published in the Proceedings of the Symposium on Thin Films: Stresses and Mechanical Properties III, Eds: W.D. Nix, J.C. Bravman, L.B. Freund and E. Arzt, Fall Meeting of the Materials Research Society, Boston, MA, December 2-6, 1991). 

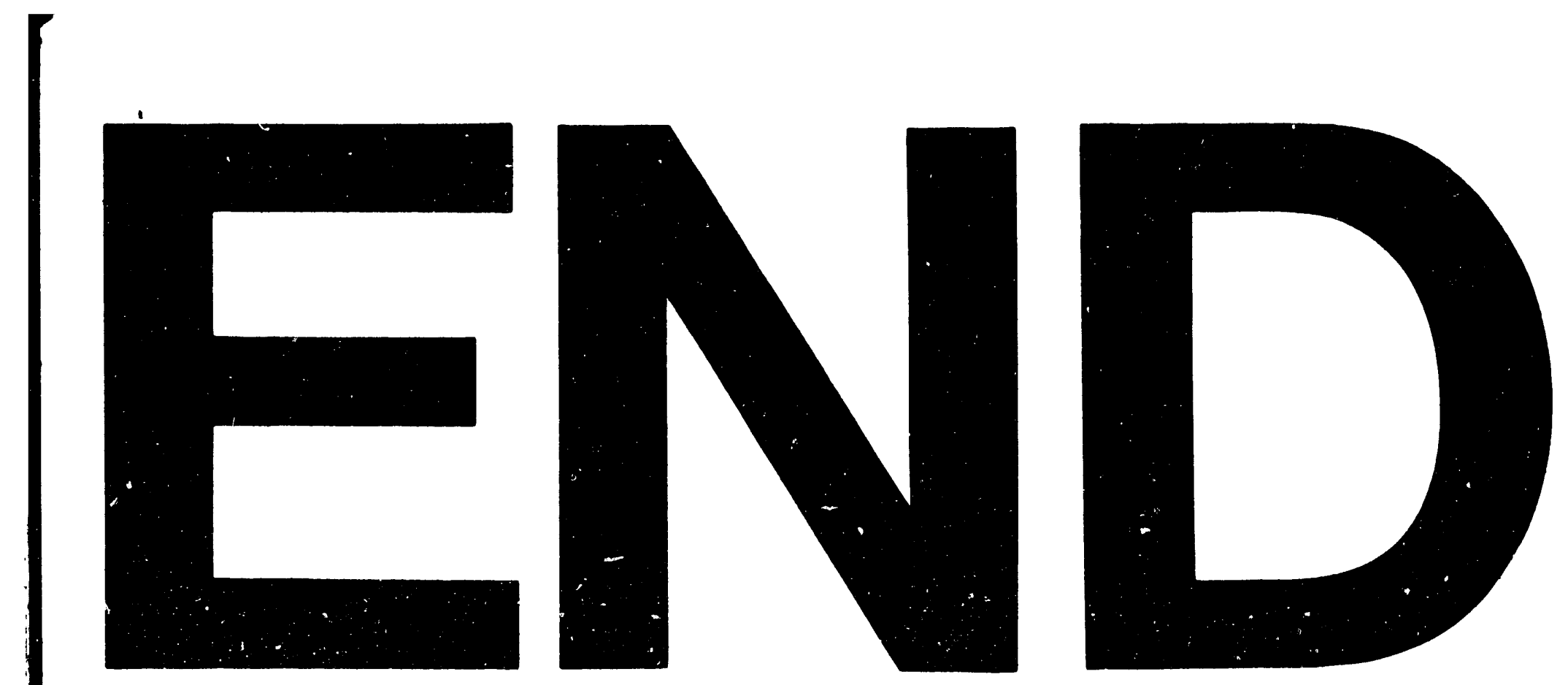

$\because$
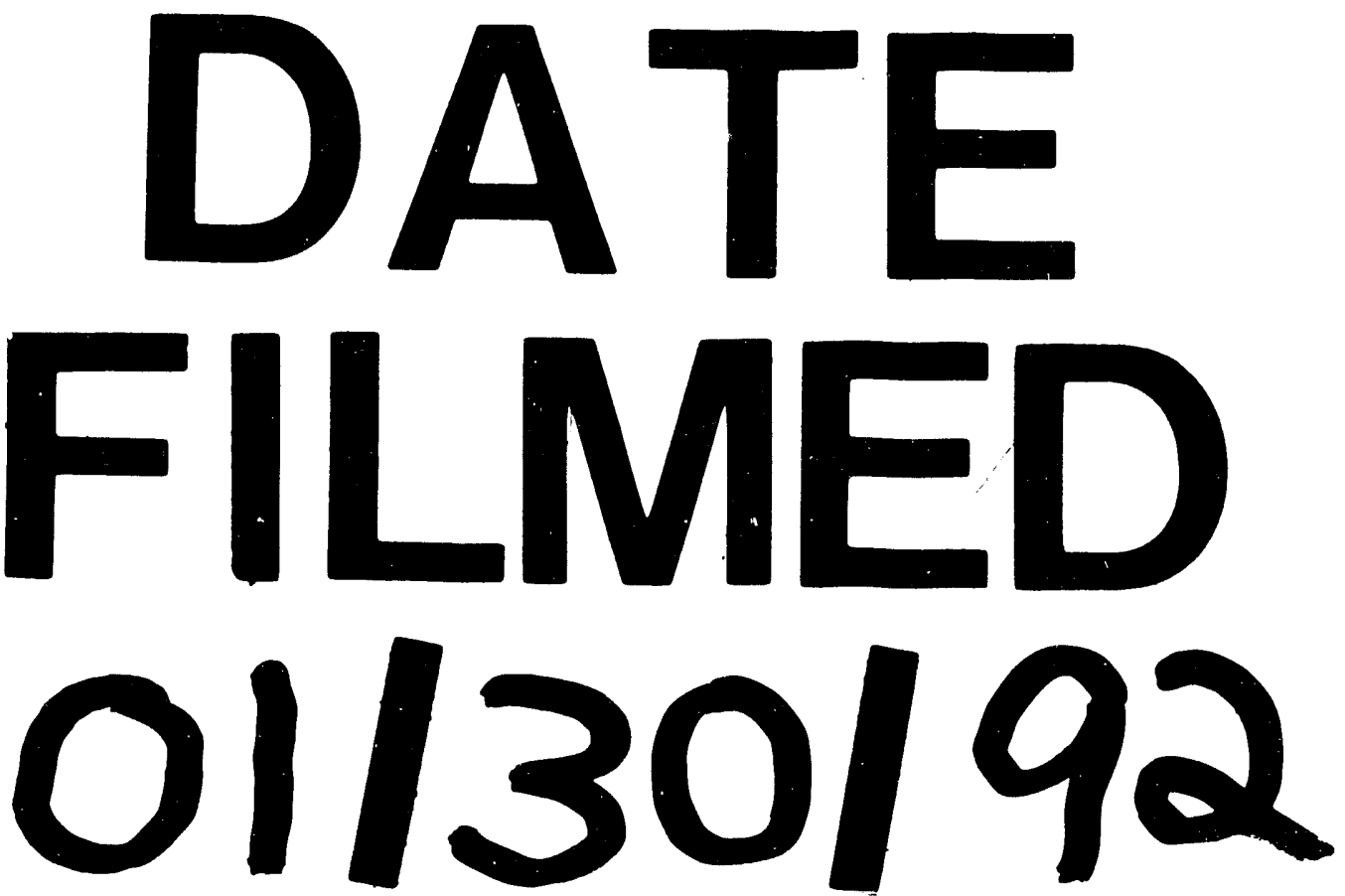
